\title{
Evolution of resistance mechanisms and biological characteristics of rifampicin- resistant Staphylococcus aureus strains selected in vitro
}

\author{
Chong Wang ${ }^{1}$, Renchi Fang ${ }^{1}$, Beibei Zhou' ${ }^{1}$ Xuebin Tian², Xiucai Zhang ${ }^{1}$, Xiangkuo Zheng ${ }^{2}$, Siqin Zhang ${ }^{1}$, \\ Guofeng Dong ${ }^{2}$, Jianming $\mathrm{CaO}^{2^{*}}$ and Tieli Zhou ${ }^{\text {* }^{*}}$ (D)
}

\begin{abstract}
Background: We aimed to determine the evolutionary pathways of rifampicin resistance in Staphylococcus aureus, and the impact of resistance mutations in the rpoB gene on fitness.

Methods: Three clinical strains and one reference strain were used to select for rifampicin-resistant $S$. aureus variants. The mutations responsible for rifampicin resistance in all of the selected isolates in vitro were investigated by polymerase chain reaction (PCR) and DNA sequencing. To compare the fitness cost of $r p o B$ mutations against their corresponding original isolates, we performed bacterial growth curve assays, static biofilm assays, in vitro competition experiments and an infection model of Galleria mellonella larvae.

Results: We obtained four rifampicin-resistant $S$. aureus isolates that showed high levels of resistance to rifampicin with a minimal inhibitory concentration (MIC) of $128 \mathrm{mg} / \mathrm{L}$, and all isolates had a mutation at position 481 (H481F/ Y) in RpoB. A broth microdilution assay indicated that mutation of H481F/Y did not affect susceptibility to common antibacterial drugs but slightly increased the vancomycin MIC. To identify the pathways involved in the development of rifampicin resistance, 32 variants (eight mutants for each strain) and four original isolates were selected for gene sequencing. Different generations of isolates were found to harbor various mutations sites. Compared with the corresponding original isolates, an in vitro fitness assay of the variant isolates showed that growth and virulence were reduced, with a statistically significantly decreased fitness, whereas the capacity for biofilm formation was elevated.
\end{abstract}

Conclusions: Our findings suggested that the acquisition of rifampicin resistance in S. aureus was dynamic and was associated with a significant fitness cost.

Keywords: Staphylococcus aureus, Rifampicin resistance, Drug resistance evolution, Fitness cost

\section{Background}

Staphylococcus aureus is one of the major human pathogens that causes a remarkable spectrum of disease, ranging from skin infections to life-threatening endocarditis with significant morbidity and mortality in both men and women of all ages $[1,2]$. The widespread increase in

\footnotetext{
* Correspondence: wzcjming@163.com; wyztli@163.com

${ }^{2}$ School of Laboratory Medicine and Life Sciences, Wenzhou Medical University, Wenzhou, Zhejiang Province, China

'Department of Clinical Laboratory, The First Affiliated Hospital of Wenzhou Medical University, Wenzhou, Zhejiang Province, China
}

resistance to antimicrobials, such as vancomycin and daptomycin, and in particularly to methicillin, as a result of the misuse of antibiotics, constitutes a global challenge for the treatment of infections caused by S. aureus [3].

Rifampicin is an antimicrobial agent that inhibits transcription via binding to the $\beta$-subunit of the bacterial DNA-dependent RNA polymerase, which is encoded by the $r p o B$ gene [4], and is used in combination therapy for serious S. aureus infections [5]. Unfortunately, the frequency of rifampicin resistance among $S$. aureus isolates has increased dramatically over recent times. An

(C) The Author(s). 2019 Open Access This article is distributed under the terms of the Creative Commons Attribution 4.0 International License (http://creativecommons.org/licenses/by/4.0/), which permits unrestricted use, distribution, and 
antimicrobial susceptibility surveillance study conducted in South Africa showed that $52.8 \%$ of multidrug-resistant $S$. aureus (MRSA) isolates from public laboratories were rifampicin-resistant during 2005 and 2006 [6], and the percentage of RIF-R MRSA isolates increased rapidly from $15.5 \%$ (in 2004) to $50.2 \%$ (in 2008) in China [7]. Rifampicin resistance is caused by mutations in a highly conserved region of the rров gene, known as the rifampicin resistance-determining region [8].

Previous studies have demonstrated that some mutations in the rроB gene could alter $S$. aureus susceptibility not only to rifampicin, but also to other last-line antibiotics such as vancomycin and daptomycin [9]. Interestingly, different mutations have been found to have different impacts on pathogenesis. For example, the RIF$\mathrm{R}$ mutation rpoB-H481Y has been associated with persistent infection via attenuated host innate immune responses [10], whereas the RIF-R mutation rpoBA477D was found to confer a range of phenotypes showing extracellular matrix thickening [11]. Because mutations in the $r p o B$ gene play a key role in the resistance of $S$. aureus to rifampicin, it is important to fully elucidate the effect of particular mutations on the phenotype of antibiotic resistance. Here, three clinical strains were used to select for rifampicin-resistant variants in vitro. We aimed to elucidate the pathways involved in the development of rifampicin resistance and to investigate the impact of $r p o B$ mutations on phenotype, virulence and susceptibility to other antibacterial agents.

\section{Methods}

\section{Bacterial isolates}

Three S. aureus isolates (SA247, SA252, SA1370) were collected from the First Affiliated Hospital of Wenzhou Medical University in China. SA247 was isolated from sputum, and SA252 and SA1370 were isolated from wounds. All three isolates were susceptible to rifampicin (RIF-S) (minimum inhibitory concentration $(\mathrm{MIC})=$ $0.25 \mathrm{mg} / \mathrm{L}$ ), and were used to select for the development of rifampicin resistance. All isolates were identified by matrix-assisted laser desorption/ionization time of flight mass spectrometry (MALDI-TOF MS) using a Vitek mass spectrometer (BioMerieux, Lyons, France). In addition, S. aureus ATCC 25923 was used as a control strain. The strains were transferred from blood agar plates to trypsin soy broth (TSB) and were recultured for $18 \mathrm{~h}$ for further analysis.

\section{In vitro selection of RIF-R strains}

An adaptation test was conducted according to the method reported previously with slight modifications [12]. Four susceptible isolates were used to select for rifampicin-resistant variants. An overnight culture of each isolate, grown in cation-adjusted Mueller-Hinton broth $(\mathrm{CAMHB})$, was adjusted to an $\mathrm{OD}_{600}=0.1$, and $30 \mathrm{~mL}$ were inoculated into tubes containing $3 \mathrm{~mL}$ of MHB with graded concentrations of rifampicin: (1) $1 /$ $2 \times \mathrm{MIC}$; (2) $1 \times \mathrm{MIC}$; (3) $2 \times \mathrm{MIC}$; and (4) $4 \times \mathrm{MIC}$. All tubes were incubated at $37^{\circ} \mathrm{C}$ overnight without shaking in the dark. The next day, the tube with visible growth at the highest rifampicin concentration was used as inoculum for the next series of tubes with increasing drug concentrations. This procedure was repeated for 15 days. The samples were passaged for 6 days in CAMHB without rifampicin and had their MICs determined again to check the stability of the phenotype.

\section{Antimicrobial susceptibility testing}

The MICs of several antimicrobials (including cefazolin, rifampicin, vancomycin, oxacillin, clindamycin, cotrimoxazole, minocycline, linezolid, azithromycin and clarithromycin) for the wild-type strains and their corresponding resistant strains were determined by the broth microdilution method in accordance with the guidelines of the Clinical and Laboratory Standards Institute 2016 [13]. The MICs of rifampicin were interpreted according to the European Committee on Antimicrobial Susceptibility Testing 2016 breakpoints [14]. Escherichia coli ATCC 25922 and S. aureus ATCC 29213 were used as control strains.

\section{PCR detection and sequencing of resistance genes}

The $r p o B$ gene was amplified by PCR using the primers rpobSP1F-5'-TTATGCTGCACCTTCGTG-3' and rpobSP 5R-5'-CAAGTGCCCATACCTCCCATC-3', designed to amplify the entire region of interest. The genomic DNAs of the isolates were extracted using the Biospin Bacterial Genomic DNA Extraction kit (Bioflux, Tokyo, Japan) and were employed as the templates for PCR amplification. The PCR products were sequenced by Shanghai Genomics Institute Technology Co. Ltd. (Shanghai, China). The obtained nucleotide sequences were analyzed and compared by BLAST searches against the NCBI database (www.ncbi.nl m.nih. gov/BLAST).

\section{Bacterial growth curve with kinetic parameters}

The $S$. aureus isolates were cultured in TSB at $37^{\circ} \mathrm{C}$ for $24 \mathrm{~h}$ to obtain bacterial growth curves. Overnight culture was then transferred to fresh TSB at a ratio of 1 to 100 and incubated at $37^{\circ} \mathrm{C}$ without agitation. The optical density of the bacterial culture at $595 \mathrm{~nm}\left(\mathrm{OD}_{595}\right)$ was measured after 0 to $24 \mathrm{~h}$ of incubation. Experiments were performed in duplicate, and the averages were used for estimating growth parameters. 


\section{Static biofilm assays}

Biofilm determination was conducted according to a previous report with minor modifications [15]. S. aureus isolates were incubated statically overnight at room temperature in 96-well plates containing TSB and were subsequently diluted 1:50 in $100 \mathrm{~mL}$ of TSB in duplicate 96-well plates (Falcon; BD Biosciences, San Jose, CA, USA). Following $24 \mathrm{~h}$ incubation at $37^{\circ} \mathrm{C}$, planktonic bacteria were decanted and the wells were washed twice with distilled water. Biofilms attached to the well surfaces were stained for 15 mins at room temperature with $125 \mathrm{~mL}$ of $0.1 \%(\mathrm{w} / \mathrm{v})$ Crystal Violet solution (Sigma-Aldrich). The Crystal Violet solution was decanted and wells were subsequently washed twice with distilled water. The bound dye was solubilized from adherent cells with $33 \%$ acetic acid and subsequently quantified by measuring the absorbance at $595 \mathrm{~nm}$. The data for each strain represented average values taken from four replicate wells performed in two independent experiments.

\section{In vitro competition experiments}

Experiments were performed to measure the in vitro competition between resistant and susceptible strains. Exponentially growing cells of the corresponding and strain were mixed in a 1:1 proportion and resuspended in $0.9 \%$ saline solution. Approximately $10^{3}$ cells from each mixture were inoculated into $10-\mathrm{ml}$ flasks of LB broth and grown at $37^{\circ} \mathrm{C}$ and $180 \mathrm{rpm}$ for 16 to $18 \mathrm{~h}$, which corresponds to approximately 20 cell generations. Serial 10-fold dilutions were plated in duplicate onto LB agar (LBA) without drug and LBA with $32 \mu \mathrm{g} / \mathrm{mL}$ of rifampicin in order to determine, respectively, the total number of CFU and the CFU of the rifampicin-resistant strains, after overnight incubation at $37{ }^{\circ} \mathrm{C}$. The competition index (CI) was defined as the ratio between the CFU of the rifampicin-resistant strain and the rifampicin-susceptible strain. The CI values were calculated for each independent competition assay, and the median values were calculated too.

\section{Infection model of Galleria mellonella larvae}

G. mellonella killing assays were carried out as described previously with slight modifications [16]. G. mellonella was used as an in vivo infection model to compare the virulence differences between resistant and susceptible strains. Twelve caterpillars weighing between 200 and $250 \mathrm{mg}$ were randomly selected for each isolate. Larvae were injected with $10 \mu \mathrm{L}$ of bacterial suspension containing $5 \times 10^{8} \mathrm{CFU} / \mathrm{mL}$ dilutions in phosphate-buffered saline (PBS), into the last left proleg using a $25 \mu \mathrm{L}$ Hamilton precision syringe. Uninfected larvae (12 untreated or injected with $10 \mu \mathrm{L}$ PBS) were used as a control. The insects were incubated at $37^{\circ} \mathrm{C}$ in the dark and were observed after 24, 48 and $72 \mathrm{~h}$. Insects were considered dead when they repeatedly failed to respond to physical stimuli. The primary outcome for the insect model was rapidity and extent of mortality of G. mellonella, as assessed by Kaplan-Meier analysis.

\section{Statistical analysis}

All statistical data were calculated by SPSS 17.0 (SPSS Inc., IL, USA). For the colony counting assay, the unpaired Student's $t$-test (two-tailed) was used. Calculated $P$ values of $<0.05$ were considered to indicate statistical significance.

\section{Results}

In vitro selection of RIF-R isolates

To identify pathways involved in the development of rifampicin resistance, three rifampicin-susceptible isolates and S. aureus ATCC 25923 were exposed to graded levels of the drug, with a starting concentration of 0.125 $\mathrm{mg} / \mathrm{L}$. After eight generations of selection and passaging for 6 days in MHB without rifampicin, a total of 32 variant strains (eight from each isolate) from the four original strains were obtained: SA247 (1st-8th); SA252 (1st-8th); SA1370 (1st-8th); SA25923 (1st-8th) (the number represents the corresponding generation). All of the eighth generation (8th) strains that had been passaged for 6 days expressed high level rifampicin resistance (SA247R, SA252R, SA370R, SA25923R; rifampicin $\mathrm{MIC}=128 \mathrm{mg} / \mathrm{L}$ ).

\section{Antimicrobial susceptibility patterns}

Antimicrobial susceptibility testing by the broth microdilution method revealed that three original strains were susceptible to all of the tested antimicrobials, except penicillin, in this study. The sensitivity of the 8th generation strains were consistent with the corresponding original strains, with the exception of rifampicin. The resistance phenotypes determined for the $S$. aureus isolates are shown in Table 1.

\section{Distribution of mutations associated with rifampicin resistance}

To identify changes that correlated with rifampicin resistance acquisition, all of the strains were selected for gene sequencing. All four independent experiments followed the same evolutionary trajectory in achieving rifampicin resistance, and the results are shown in Table 2. Via sequencing analysis, no amino acid substitutions were observed in the RpoB protein of the 1st generation strains; however, the specific amino acid mutated varied among the 2nd to 8th generation strains. Within 6 days of passage, all 8th generation strains harbored at least a single amino acid substitution in the protein encoded by the $r p o B$ gene. 
Table 1 MICs of the antibiotics tested in the current study

\begin{tabular}{|c|c|c|c|c|c|c|c|c|c|c|c|}
\hline \multirow[t]{2}{*}{ Strains } & \multicolumn{11}{|c|}{ MIC (mg / L) } \\
\hline & RIF & VAN & TEC & GEN & LNZ & TCY & ERY & CIP & OXA & CLI & CZO \\
\hline SA247 & 0.25 & 0.25 & 0.25 & 0.5 & 2 & 0.25 & 0.25 & 0.25 & 0.5 & 0.25 & 0.25 \\
\hline SA247R & 128 & 0.5 & 1 & 0.5 & 2 & 0.25 & 0.25 & 0.25 & 0.5 & 0.25 & 0.25 \\
\hline SA252 & 0.25 & 0.5 & 0.25 & 0.5 & 2 & 0.25 & 0.25 & 0.5 & 0.25 & 0.25 & 0.5 \\
\hline SA252R & 128 & 1 & 1 & 0.5 & 2 & 0.25 & 0.25 & 0.5 & 0.25 & 0.25 & 0.5 \\
\hline SA1370 & 0.25 & 0.25 & 0.5 & 0.5 & 1 & 0.25 & 64 & 4 & 0.25 & 4 & 0.25 \\
\hline SA1370R & 128 & 1 & 1 & 0.5 & 1 & 0.25 & 64 & 4 & 0.25 & 4 & 0.25 \\
\hline ATCC 25923 & 0.25 & 0.25 & 0.5 & 0.5 & 1 & 0.25 & 0.25 & 0.5 & 0.25 & 0.25 & 0.25 \\
\hline ATCC25923R & 128 & 0.5 & 1 & 0.5 & 1 & 0.25 & 0.25 & 0.5 & 0.25 & 0.25 & 0.25 \\
\hline
\end{tabular}

MICS minimum inhibitory concentrations; RIF rifampicin; VAN vancomycin; TEC teicoplanin; GEN gentamicin; $L N Z$ linezolid; TCY tetracycline; ERY erythromycin; CIP ciprofloxacin; OXA oxacillin; CLI clindamycin; CZO cefazolin

\section{Resistance to rifampicin associated with a fitness cost in}

\section{S. aureus}

To assess whether the evolution of rifampicin resistance strains was accompanied by an associated fitness cost, we measured bacterial growth curves and analyzed biofilm formation ability for all strains derived from this study. Growth curves revealed that the growth rates were faster for the original strains than for the corresponding 8th generation strains (Fig. 1 and Additional file 1). The biofilmforming ability was variable among strains from different patients. When compared with the corresponding original strains, the biofilm formation ability of the resistant strains was changed (Fig. 2 and Additional file 2). In vitro competition experiments, we observed a marked decrease in fitness for these strains, as shown by the competition index $(\mathrm{CI})$ results in Fig. 3 and Additional file 3. The greatest decrease was observed for the SA252 strain, with a median CI of 0.26 , followed by the SA1370, ATCC25923 and SA247 isolates, with median CIs of $0.34,0.55$ and 0.61 , respectively.

\section{Infection model of Galleria mellonella larvae}

To determine the virulence of strains with rifampicin resistant and sensitive phenotypes, larvae were injected with $5 \times$ $10^{8} \mathrm{CFU}$ of bacterial suspension and their survival was monitored (Fig. 4 and Additional file 4). At $96 \mathrm{~h}$ post-infection, the mortality of larvae was lower for RIF-R S. aureus isolates compared with the corresponding RIF-S strains. No mortality was observed in the control injected with PBS.

\section{Discussion}

Despite effective antibiotics and constant improvements in patient care, $S$. aureus infections are still common in both hospitals and the community. Unfortunately, early intervention with appropriate antimicrobial therapies, such as daptomycin and vancomycin, is becoming less effective [10]. Therefore, the treatment of $S$. aureus infections with combination therapy remains an area of active research interest. Rifampicin shows activity against $S$. aureus and is one of the drugs used in combination therapy [5]. However, increasing rifampicin resistance caused by mutations in the $r p o B$ gene encoding RNA polymerase has been detected, challenging the use of recommended treatment regimens [17]. The molecular mechanisms underlying rifampicin resistance in $S$. aureus were investigated. Many previous studies have demonstrated that mutations in a conserved region of the $r p o B$ gene, known as the rifampicin resistance-determining region, are responsible for rifampicin resistance, but

Table 2 MIC and mutation of each generation of strains

\begin{tabular}{|c|c|c|c|c|c|c|c|c|c|c|}
\hline \multirow[t]{2}{*}{ Strains } & \multicolumn{10}{|c|}{ Generations } \\
\hline & & Oth & 1th & 2th & 3th & 4th & 5 th & 6th & 7th & 8th \\
\hline \multirow[t]{2}{*}{ SA247R } & $\mathrm{MIC}$ & 0.25 & 0.25 & 1 & 2 & 4 & 4 & 8 & 32 & 128 \\
\hline & Mutation & - & - & - & H481L & H481L & H481L & H481L & H481F & H481F \\
\hline \multirow[t]{2}{*}{ SA252R } & $\mathrm{MIC}$ & 0.25 & 0.25 & 0.5 & 2 & 4 & 8 & 16 & 64 & 128 \\
\hline & Mutation & - & - & - & - & - & - & H481Y & H481Y & H481Y \\
\hline \multirow[t]{2}{*}{ SA1370R } & MIC & 0.25 & 0.25 & 0.5 & 1 & 2 & 8 & 16 & 32 & 128 \\
\hline & Mutation & - & - & - & - & - & - & S464P & H481Y/S464P & H481Y/S464P \\
\hline \multirow[t]{2}{*}{ ATCC 25923R } & MIC & 0.25 & 0.25 & 1 & 2 & 4 & 16 & 32 & 64 & 128 \\
\hline & Mutation & - & - & - & $\mathrm{R} 484 \mathrm{H}$ & S464P & S464P & S464P & H481Y/S464P & H481Y/S464P \\
\hline
\end{tabular}


A

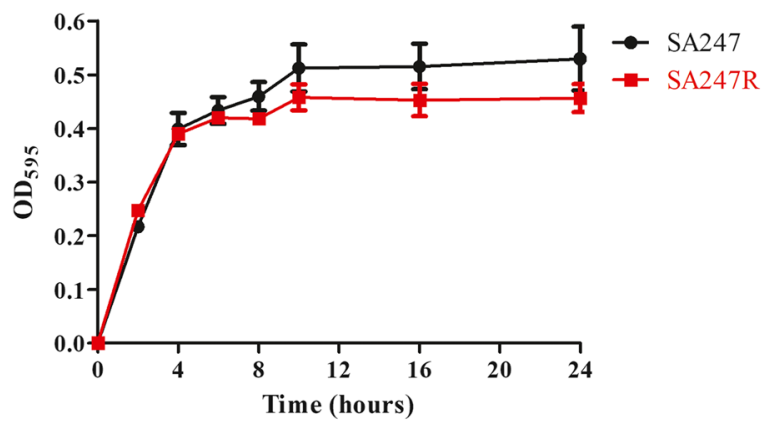

C

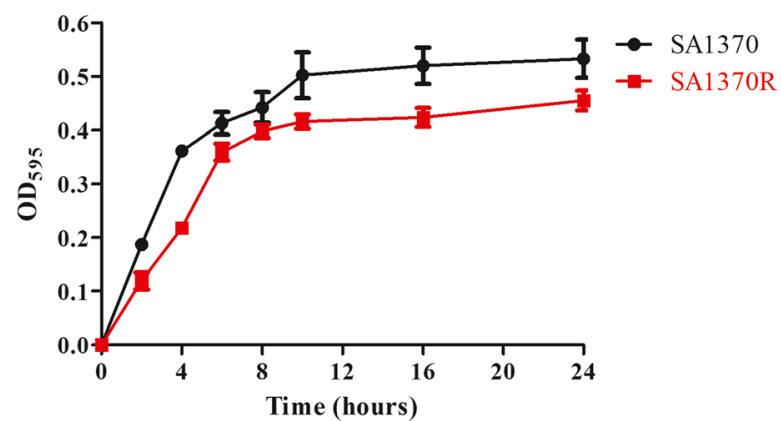

B

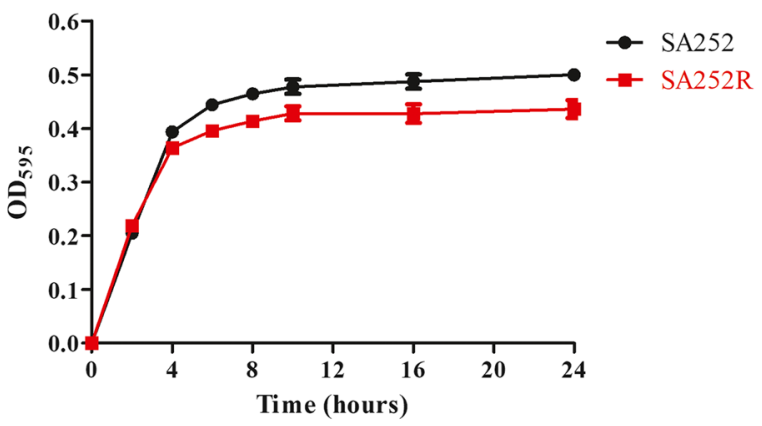

D

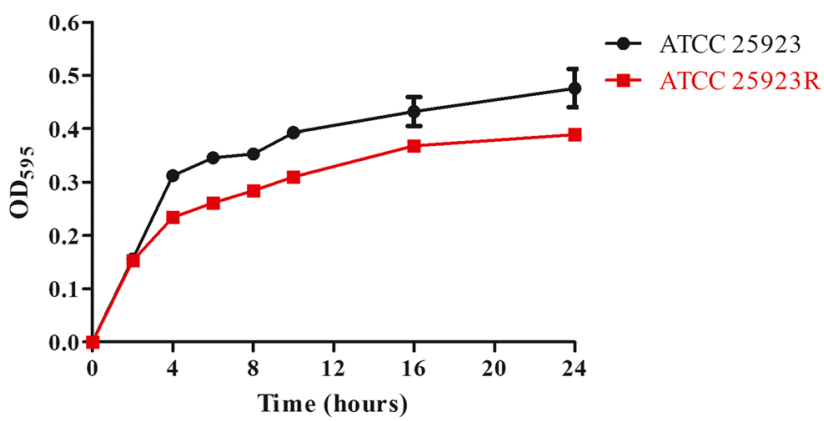

Fig. 1 Bacterial growth curves for all strains derived in this study. (a) Growth curves for SA247 (original strain) and SA247R (8th generation strain); (b) growth curves for SA252 and SA252R; (c) growth curves for SA1370 and SA1370R; (d) growth curves for ATCC 25923 and ATCC $25923 R$

little has been reported regarding the pathways involved in the development of rifampicin resistance. The purpose of this study was to determine the $r p o B$ gene mutations that confer RIF-R in $S$. aureus strains during the process of in vitro selection and the phenotypic consequences linked to rifampicin resistance.

In the present study, we obtained four RIF-R S. aureus strains with rifampicin $\mathrm{MICs}>128 \mathrm{mg} / \mathrm{L}$ via in vitro

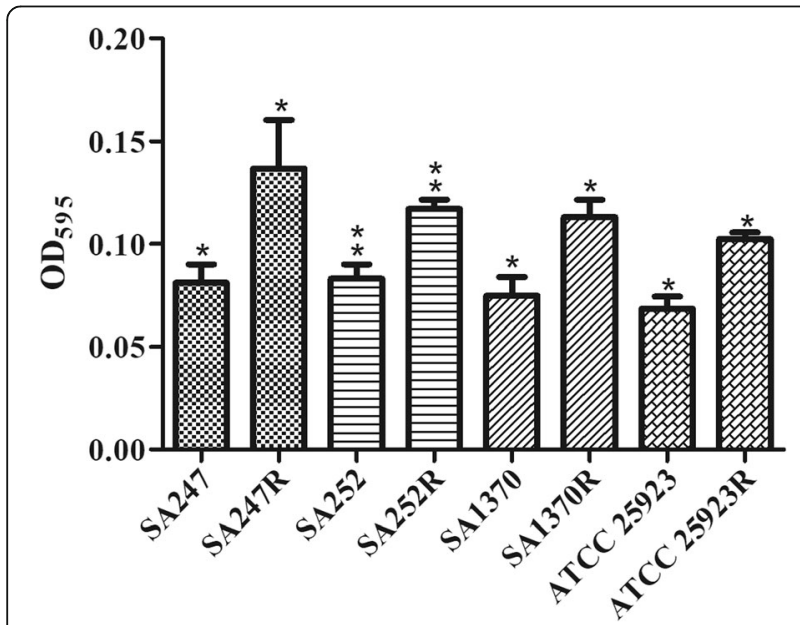

Fig. 2 The biofilm formation ability of all strains derived in this study selection. As one of the drugs used in combination therapy, rifampicin resistance compromises susceptibility to other last-line antibiotics such as vancomycin and daptomycin. Drug susceptibility screening of $S$. aureus showed that only rifampicin-resistant strains differed significantly from the original strains. Some reports have suggested that the rate of rifampicin resistance is clinically

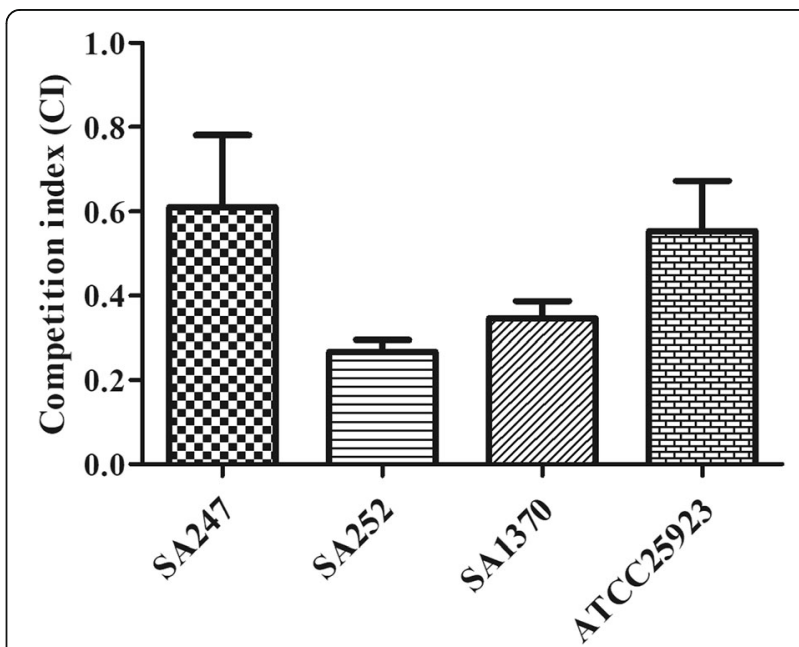

Fig. 3 In vitro competition index $(\mathrm{Cl})$ results of all strains derived in study 


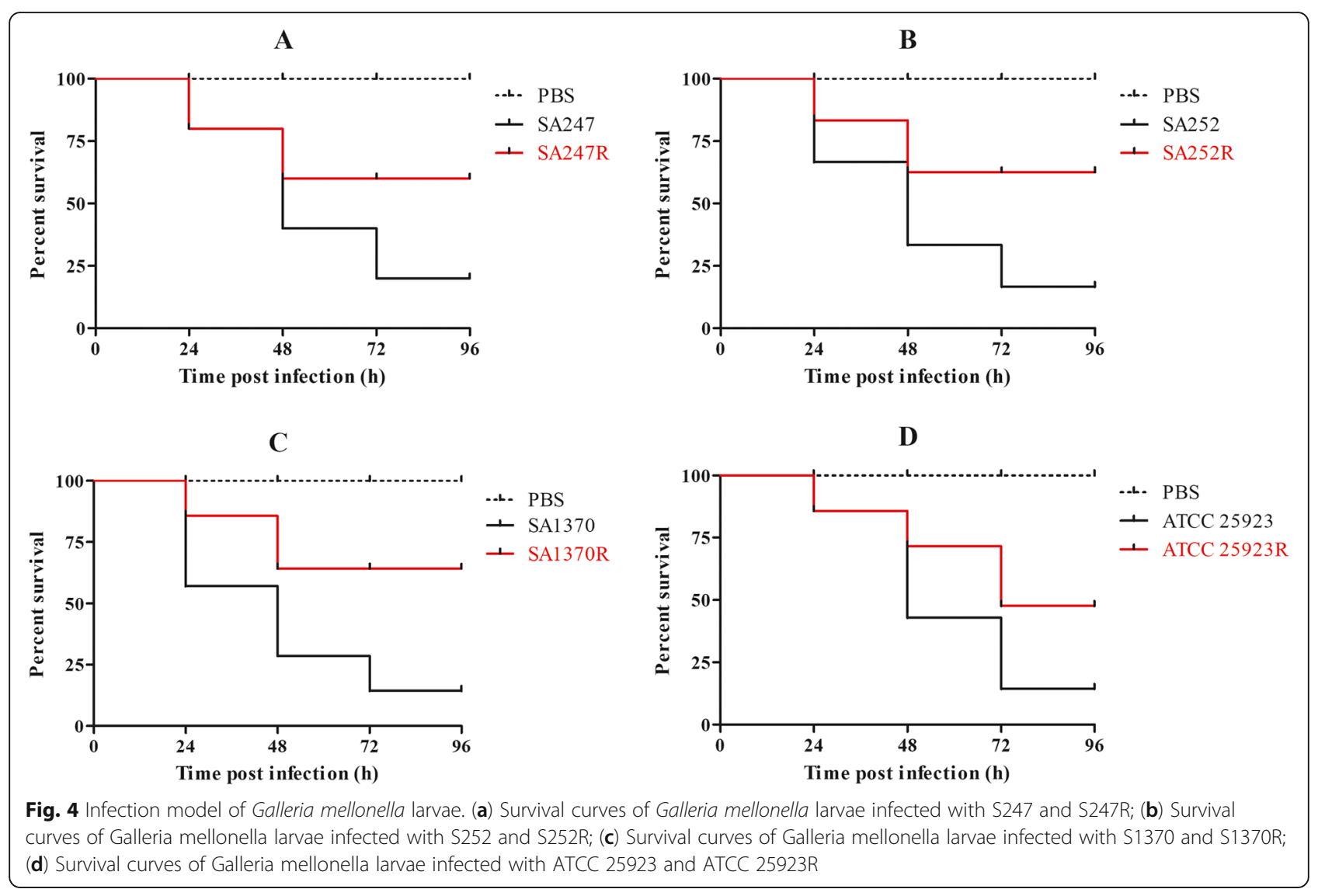

significant when used in monotherapy, this may be because the evolution of antimicrobial resistance is increased compared with combination therapy [18]. With rifampicin resistance being so easily acquired, it seems inappropriate to consider rifampicin monotherapy for the treatment of $S$. aureus infection. However, research has shown that certain mutations in the $r p o B$ gene are associated with alterations in vancomycin susceptibility in $S$. aureus. Here, we amplified and sequenced portions of the rpoB gene from RIF-R $S$. aureus strains, and a H481Y point mutation was the only substitution detected among them. As described in the literature, position 481 of RpoB presents a hot-spot for amino acid residue replacement and has recently been found to be the strongest genetic marker of increased vancomycin resistance $[19,20]$. A previous study confirmed that $\mathrm{H} 481 \mathrm{Y}$ is associated with decreased susceptibility to vancomycin by genetic reconstruction [21]. Of interest is the observation that all strains were susceptible to vancomycin $(\mathrm{MIC}=1 \mathrm{mg} / \mathrm{L})$, suggested that this mutational change was not associated with resistance to vancomycin.

Previous studies have shown that high level rifampicin resistance may be attributed to multiple mutations, indicating a step-by-step mechanism in resistance development [22]. Therefore, dynamic changes in the rifampicin resistance of $S$. aureus strains are of urgent concern. All of the strains obtained in our experiments were subjected to genome sequencing, to identify changes that correlated with the acquisition of rifampicin resistance. Sequencing revealed that the mutations were dynamic and remained stable until high levels of resistance were achieved. These mutations may indicate genetic drift or may reflect the selective pressure imposed by rifampicin for a strain to develop resistance.

Notably, certain rifampicin alleles often lead to adapted strains having different physiological characteristics compared with their original strains. To verify these physiological characteristics, we conducted in vitro adaptability tests, including growth curve analysis, biofilm formation ability assays, in vitro competition experiments and an infection model of G. mellonella larvae. To determine whether rifampicin resistance acquired in vitro may impact virulence traits in S. aureus, G. mellonella was used as an in vivo model. Worms injected with PBS showed $100 \%$ survival at day 4, but those injected with the original strains displayed low survival rates. A similar trend was observed with strain ATCC 25923, although the survival rate was higher than with the original $S$. aureus strain. The growth curves of each 
resistant strain were lower than their original strains, suggesting that RIF-R is associated with a reduction in the virulence fitness cost. However, these mutations in the rрoB gene could induce biofilm formation. The ability to form a biofilm is an important virulence factor, and we have previously reported that biofilm production is a sort of defense reaction of S. aureus [23]. The outcome of the competition process depends on the relative fitness, defined as the efficacy of multiplication of the resistant cell compared with that of the susceptible cell. And, the data showed that the median CI values for these strains were associated with a statistically significantly decreased fitness in the in vitro experiments. Based on the above results, we hypothesize that when selecting for RIF-R $S$. aureus clones carrying specific rpoB mutations conferring a lower fitness cost and adaptive positive pleiotropic effects, stable conversion to rifampin-resistant lineages can occur.

\section{Conclusions}

In conclusion, we found that rifampicin resistance was closely associated with $r p o B$ gene mutations. Our results also showed that mutations in the $r p o B$ gene were not associated with decreased susceptibility to vancomycin in $S$. aureus. It is worth noting that rifampicin is the major selective pressure driving rроB evolution, and plays a key role in enhancing pathogenicity. Therefore, rational use of antibiotics is important to prevent the emergence of resistant bacteria.

\section{Additional files}

Additional file 1: Table S1. The details of bacterial growth curves for all strains derived in this study, the optical density of the bacterial culture at $595 \mathrm{~nm}$ was measured after 0 to $24 \mathrm{~h}$ of incubation. Experiments were performed in duplicate, and the averages were used for estimating growth parameters. (DOCX $41 \mathrm{~kb}$ )

Additional file 2: Table S2. The details of biofilm formation ability of all strains derived in this study, quantified by measuring the absorbance at $595 \mathrm{~nm}$, and the data for each strain represented average values taken from four replicate wells performed in two independent experiments. (DOCX $20 \mathrm{~kb}$ )

Additional file 3: Table S3. The details of in vitro competition index (Cl) results of all strains derived in this study, Cl was defined as the ratio between the CFU of the rifampicin-resistant strain and the rifampicinsusceptible strain. (DOCX $18 \mathrm{~kb}$ )

Additional file 4: Table S4. The details of infection model of Galleria mellonella larvae, larvae were injected with $5 \times 108$ CFU of bacterial suspension and their survival was monitored, at $96 \mathrm{~h}$ post-infection, the mortality of larvae was lower for RIF-R S. aureus isolates compared with the corresponding RIF-S strains. (DOCX $17 \mathrm{~kb}$ )

\section{Abbreviations}

MALDI-TOF MS: Matrix-assisted laser desorption/ionization time of flight mass spectrometry; MIC: Minimum inhibitory concentration; PCR: Polymerase chain reaction

Acknowledgements

Not applicable.

\section{Authors' contributions}

CW, TLZ and JMC designed the study. CW, BBZ, RCF, XBT, SQZ and XCZ performed the research. CW, XKZ, GFD and XCZ performed the data analysis. CW and RCF wrote the manuscript. TLZ and JMC supervised the research. All authors read and approved the final version of the manuscript.

\section{Funding}

This work was supported by Zhejiang Provincial Program for the Cultivation of High-level Innovative Health Talents (grant number [2012]241). The funding body provided funds for the purchase of consumption materials for the study and paid scholarships for students. The funding body has no role in the design of the study and collection, analysis, and interpretation of data and in writing the manuscript

\section{Availability of data and materials}

All data generated or analyzed during this study are included in this published article.

\section{Ethics approval and consent to participate}

Not applicable.

\section{Consent for publication}

Not applicable.

\section{Competing interests}

The authors declare that they have no competing interests.

Received: 31 January 2019 Accepted: 22 August 2019

Published online: 18 September 2019

\section{References}

1. Villanueva M, Jousselin A, Baek KT, Prados J, Andrey DO, Renzoni A, et al. Rifampin resistance $r p o B$ alleles or multicopy thioredoxin/thioredoxin reductase suppresses the lethality of disruption of the global stress regulator spx in Staphylococcus aureus. J Bacteriol. 2016;198:2719-31.

2. Roch M, Varela MC, Taglialegna A, Rose WE, Rosato AE. Activity of Telavancin against S. aureus isolated from cystic fibrosis patients including those with decreased susceptibility to Ceftaroline. Antimicrob Agents Chemother. 2018. https://doi.org/10.1128/AAC.00956-18.

3. Guerillot R, Goncalves da Silva A, Monk I, Giulieri S, Tomita T, Alison E, et al. Convergent evolution driven by rifampin exacerbates the global burden of drug-resistant Staphylococcus aureus. mSphere. 2018;3. https://doi.org/10.112 8/mSphere.00550-17.

4. Campbell EA, Korzheva N, Mustaev A, Murakami K, Nair S, Goldfarb A, et al, Structural mechanism for rifampicin inhibition of bacterial $r$ na polymerase. Cell. 2001:104:901-12.

5. Purrello SM, Garau J, Giamarellos E, Mazzei T, Pea F, Soriano A, et al. Methicillin-resistant Staphylococcus aureus infections: a review of the currently available treatment options. J Glob Antimicrob Resist. 2016;7:178-86.

6. Marais E, Aithma N, Perovic O, Oosthuysen WF, Musenge E, Duse AG. Antimicrobial susceptibility of methicillin-resistant Staphylococcus aureus isolates from South Africa. S Afr Med J. 2009:99:170-3.

7. Xiao YH, Giske CG, Wei ZQ, Shen P, Heddini A, Li LJ. Epidemiology and characteristics of antimicrobial resistance in China. Drug Resist Updat. 2011;14:236-50

8. Bongiorno D, Mongelli G, Stefani S, Campanile F. Burden of rifampicin- and methicillin-resistant Staphylococcus aureus in Italy. Microb Drug Resist. 2018; 24:732-8.

9. Cui L, Isii T, Fukuda M, Ochiai T, Neoh HM, Camargo IL, et al. An RpoB mutation confers dual heteroresistance to daptomycin and vancomycin in Staphylococcus aureus. Antimicrob Agents Chemother. 2010;54:5222-33.

10. Gao W, Cameron DR, Davies JK, Kostoulias X, Stepnell J, Tuck KL, et al. The RpoB H481Y rifampicin resistance mutation and an active stringent response reduce virulence and increase resistance to innate immune responses in Staphylococcus aureus. J Infect Dis. 2013:207:929-39.

11. Baek KT, Thogersen L, Mogenssen RG, Mellergaard M, Thomsen LE, Petersen A, et al. Stepwise decrease in daptomycin susceptibility in clinical Staphylococcus aureus isolates associated with an initial mutation in rpoB and a compensatory inactivation of the clpX gene. Antimicrob Agents Chemother. 2015;59:6983-91. 
12. Dabul ANG, Avaca-Crusca JS, Van Tyne D, Gilmore MS, Camargo ILBC. Resistance in in vitro selected Tigecycline-resistant methicillin-resistant Staphylococcus aureus sequence type 5 is driven by utations in mepR and mepA genes. Microb Drug Resist. 2018:24(5):519-26.

13. CLSI. Performance standards for antimicrobial susceptibility testing. CLSI document M100S-26th. Wayne: Clinical and Laboratory Standards Institute; 2016; 76-82.

14. European Committee on Antimicrobial Susceptibility Testing. 2016. Breakpoint tables for interpretation of MICs and zone diameters. 0. Verrsion2.http://www.eucast.org/clinical_breakpoints/.

15. Merritt JH, Kadouri DE, O'Toole GA. Growing and analyzing static biofilms. Curr Protoc Microbiol. 2005; Chapter 1:Unit 1B 1. https://doi.org/10.1002/ 9780471729259

16. Tsai CJ, Loh JM, Proft T. Galleria mellonella infection models for the study of bacterial diseases and for antimicrobial drug testing. Virulence. 2016;7:214-29

17. Brinkman CL, Schmidt-Malan SM, Mandrekar JN, Patel R. Rifampin-based combination therapy is active in foreign-body osteomyelitis after prior rifampin monotherapy. Antimicrob Agents Chemother. 2017;61. https://doi.org/10.1128/AAC.01822-16.

18. Russell CD, Lawson McLean A, Saunders C, Laurenson IF. Adjunctive rifampicin may improve outcomes in Staphylococcus aureus bacteraemia: a systematic review. J Med Microbiol. 2014;63:841-8.

19. Baines SL, Holt KE, Schultz MB, Seemann T, Howden BO, Jensen SO, van Hal SJ, Coombs GW, Firth N, Powell DR, Stinear TP, Howden BP. Convergent adaptation in the dominant global hospital clone ST239 of methicillinresistant Staphylococcus aureus. MBio. 2015;6:e00080.

20. Murphy CK, Mullin S, Osburne MS, van Duzer J, Siedlecki J, Yu X, et al. In vitro activity of novel rifamycins against rifamycin-resistant Staphylococcus aureus. Antimicrob Agents Chemother. 2006;50:827-34.

21. Matsuo M, Hishinuma T, Katayama Y, Cui L, Kapi M, Hiramatsu K. Mutation of RNA polymerase beta subunit (rpoB) promotes hVISA-to-VISA phenotypic conversion of strain Mu3. Antimicrob Agents Chemother. 2011;55:4188-95.

22. Zhou W, Shan W, Ma X, Chang W, Zhou X, Lu H, Dai Y. Molecular characterization of rifampicin-resistant Staphylococcus aureus isolates in a Chinese teaching hospital from Anhui, China. BMC Microbiol. 2012;12:240.

23. Majidpour A, Fathizadeh S, Afshar M, Rahbar M, Boustanshenas M, Heidarzadeh $\mathrm{M}$, et al. Dose-dependent effects of common antibiotics used to treat Staphylococcus aureus on biofilm formation. Iran J Pathol. 2017;12: $362-70$.

\section{Publisher's Note}

Springer Nature remains neutral with regard to jurisdictional claims in published maps and institutional affiliations.

Ready to submit your research? Choose BMC and benefit from:

- fast, convenient online submission

- thorough peer review by experienced researchers in your field

- rapid publication on acceptance

- support for research data, including large and complex data types

- gold Open Access which fosters wider collaboration and increased citations

- maximum visibility for your research: over $100 \mathrm{M}$ website views per year

At $\mathrm{BMC}$, research is always in progress.

Learn more biomedcentral.com/submissions 